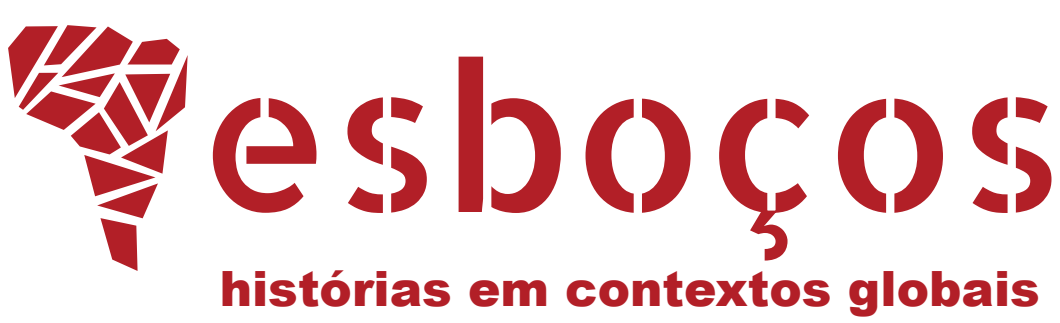

\title{
"YMAGE DEL MON": O CORPO E O MUNDO NO ATLAS CATALÃO DE CRESQUES ABRAHAM, 1375
}

"Ymage del Mon": the body and the world in the Catalan Atlas of Cresques Abraham, 1375

Aline Dias da Silveira ${ }^{a}$ (D) https://orcid.org/0000-0003-1662-5593

E-mail: aline.d.s@ufsc.br

Bianca Klein Schmitt ${ }^{\mathrm{a}}$ (D) https://orcid.org/0000-0002-3224-3002

E-mail: bischmitt98@gmail.com

a Universidade Federal de Santa Catarina, Centro de Filosofia e Ciências Humanas, Departamento de História, Florianópolis, SC, Brasil 


\title{
RESUMO
}

O presente artigo pretende compreender as inter-relações espaciais presentes no Atlas Catalão (1375) entre o corpo microcosmo e o macrocosmo, utilizando como fundamento a visão de mundo manifesta na própria fonte sobre a relação interdependente e espelhada entre ambos, a considerar que essa relação consiste em uma perspectiva amalgamada a partir dos entrelaçamentos transculturais e transtemporais. Para nossa análise, primeiramente, apresentaremos o contexto político e social da produção do Atlas Catalão e a situação específica de seu autor, o judeu Cresques Abraham (1375). Na sequência, analisaremos a representação do homem zodiacal no fólio I da fonte, utilizando o método iconológico, com o suporte teórico de Aby Warburg, Erwin Panofsky e John Brian Harley. O homem zodiacal é uma figura recorrente em iluminuras medievais, compreendida por nós como vetor entre o macrocosmo e o corpo humano, no entanto, chegamos ao resultado de que há especificidades desta representação no Atlas Catalão que o diferenciam de outros de sua época: os gestos de seus pés, mãos e olhos, bem como outras características, como a performance corporal, tamanho de barba e cabeleira, apontam para uma profunda presença da mística judaica ibérica construída a partir de confluências culturais ao longo de séculos.

\section{PALAVRAS-CHAVE}

Atlas Catalão. Homem zodiacal. Mística judaica.

\begin{abstract}
This article aims to understand the spatial interrelationships present in the Catalan Atlas (1375). We will base this analysis on the worldview manifested in the source itself about the interdependent and mirrored relationship between micro and macrocosm, which consists of an amalgamated perspective from the transcultural and transtemporal interlacing. Firstly, we will briefly present the historical context of the production of the Catalan Atlas and the specific situation of its author, the Jew Cresques Abraham (1375). Later on, we will analyse the representation of the zodiacal man on the folio I in the source with the use of the iconological method and the theoretical support of Aby Warburg, Erwin Panofsky, and John Brian Harley. The zodiacal man is a recurring figure in medieval illuminations, however, there are specificities of this representation in the Catalan Atlas that differentiate it from others of its time. The gestures of the man's feet, hands and eyes, as well as other features, such as body performance, beard and hair size, point to a profound presence of Iberian Jewish mystique built on cultural confluences over the centuries.
\end{abstract}

\section{KEYWORDS}

Catalan Atlas. Zodiacal man. Jewish mystique. 
Mapa Mundi, que podemos entender como imagem do mundo, de suas diversas idades, das regiões que existem sobre a Terra e das diversas gentes que aí habitam. ${ }^{1}$

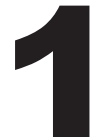

375, Maiorca, o reino de Aragão está dividido pelas divergências familiares da coroa e a disputa pela hegemonia política e econômica do Mediterrâneo ocidental. A influência política de Maiorca resulta da expansão que ocorreu há mais de um século antes, sob o reinado de Jaime I de Aragão e sua investida no processo de retomada e reorganização do espaço aragonês-catalão. Em meio a esse cenário conturbado, o "Grande Mar" ainda é o principal cenário de disputas, que precisa ser perscrutado e tecnicamente dimensionado, para que seja possível seu controle político ou, ao menos, ter seu espaço estrategicamente utilizado. Será a experiência cultural, técnica e política da Península Ibérica medieval o que possibilitará a transposição desse espaço em imagem, uma ymage del mon? Imagem do mundo, que quer dizer Mapa Mundi, como explica o judeu Cresques Abraham, autor do Atlas Catalão (1375), "de suas diversas idades, das regiões que existem sobre a terra e das diversas gentes que aí habitam" (Atlas Catalão, Folio I, apud NOGUEIRA, 2013, p. 269).

As palavras de Cresques orientam o presente artigo, o qual tem como proposta pensar a relação entre o corpo e o mundo representados no Atlas Catalão. Pelos limites permitidos a um artigo, nosso recorte cingirá a folha I, conhecida como cosmográfico, na figura humana, cujas partes estão relacionadas com os signos zodiacais, o homem zodiacal. Porque pensamos que essa imagem expressa bem a relação integrativa micro-macrocosmos de fundamento neoplatônico, que perpassa toda a fonte, a considerar que o corpo humano também foi entendido no mundo medieval como Imago mundi.

Como método, usaremos uma leitura iconológico-histórica da imagem, relacionando com seu contexto cultural e político. Seguiremos os caminhos traçados por Erwin Panofsky, mas também trabalharemos com o conceito de nachleben (pós-vida) de Warburg e a ideia de uma memória imagética comum, manifesta por Warburg no Atlas Mnemosine (WARBURG, 2015, p. 363-375).

Erwin Panofsky, em sua estada nos Estados Unidos durante a Segunda Guerra Mundial, percebeu a necessidade de distinguir iconografia de iconologia em sua obra Significado das Artes Visuais, ${ }^{2}$ especificamente no capítulo "Iconografia e Iconologia: uma introdução ao estudo da arte renascentista". O autor, entusiasta dos escritos de Aby Warburg, definiu as diferenças entre ambas as áreas da seguinte maneira:

[...] proponho reviver o velho e bom termo, "iconologia", sempre que a iconografia for tirada de seu isolamento e integrada em qualquer outro método histórico, psicológico ou crítico, que tentemos para resolver o enigma da esfinge [...]. Iconologia, portanto, é um método de interpretação que advém da síntese

\footnotetext{
${ }^{1}$ No original: "Mapa mondi vol dir aytant con ymage del mon e de les diverses etats del mon e de les regions que son sus la terra, de diversas maneras de gens qui en ela habiten". Primeiro folio do Atlas Catalão, lado A, coluna à esquerda. Tradução de Magali Nogueira (2013, p. 269) em sua tese de doutorado.

${ }^{2}$ Significado nas Artes Visuais: Primeiro escrito em alemão em 1932, depois em inglês em 1939 e complementado em 1957 (PANOFSKY, 2007).
} 
mais que da análise. E assim como a exata identificação dos motivos é o requisito básico de uma correta análise iconográfica, também a exata análise das imagens, estórias e alegorias é o requisito essencial para uma correta interpretação iconológica (PANOFSKY, 2007, p. 57).

Claramente, nas palavras de Panofsky, iconologia e iconografia não são excludentes, mas complementares. Dessa forma, a proposta de fazer uma análise iconológica traz em si também a necessidade de certa descrição e análise iconográfica, mas a transcende, buscando seus significados simbólico, alegórico e vinculações históricas para além de seu próprio contexto. Por isso, Panofsky falou de síntese, porque o método iconológico converge diversos aspectos de significados em uma síntese expressa na imagem.

Essa definição de iconologia deriva da obra de Abraham Moritz Warburg - Aby Warburg - que desenvolveu o método de análise da obra de arte em confluência com outras expressões artísticas, como estátuas, rituais, textos literários, científicos e filosóficos. Ou seja, não é uma análise da obra somente por ela mesma em si, mas dentro de um sistema maior de perceber a relação do humano (em todos os aspectos) com a natureza ou cosmos. A erudição de Aby Warburg o permitia trilhar caminhos de uma longa temporalidade na busca da herança antiga, seja na Grécia, na Mesopotâmia, na Índia ou em aldeias indígenas norte-americanas. Em sua busca, ele cunhou o conceito de nachleben, que muitos traduzem como sobrevivência, mas que nós, neste artigo, preferimos traduzir com pós-vida, pois entendemos que há uma ressignificação da presença antiga.

Dentro dessa perspectiva, primeiramente apresentaremos o contexto de Abraham Cresques, enquanto judeu da aljama ${ }^{3}$ de Maiorca, sua família e as possíveis fontes com as quais trabalhou para a construção do mapa, principalmente, na escrita das duas primeiras folhas de seu "Mapa Mundi". No segundo momento, trataremos, mais especificamente, da imagem humana da primeira folha e a relação tempo-espaço-humanidade que ela presentifica enquanto símbolo de essência não corrompida, o homem microcosmo. Para tanto, cruzaremos o texto da fonte com outros textos e imagens medievais que versam sobre o tema, como o Gayat al-Hakim (séc. XI), conhecido como o Picatrix (séc. XIII) e o Haggadah de Barcelona (séc. XIV).

\section{A COROA DE ARAGÃO, OS JUDEUS E CRESQUES ABRAHAM}

A análise das interconexões de aspectos políticos, econômicos e culturais pode ser capaz de revelar com maior profundidade como a articulação de diversos elementos e contextos proporcionou a produção do Atlas Catalão no século XIV.

O contexto do espaço mediterrânico nos séculos XIII e XIV era de muita agitação. As disputas de Aragão, França e cidades italianas pelas ilhas mediterrânicas estratégicas chegaram à região de Baleares, assim como à Sicília e à Sardenha. Esses territórios

\footnotetext{
${ }^{3}$ Aljama é uma entidade autônoma que reunia judeus sob uma mesma jurisdição. Internamente, possuía direitos jurídicos para julgar no quesito religioso, civil e criminal. Externamente, a entidade judaica era regulada por meio de suas relações com a Coroa. Dessa forma, os judeus estavam submetidos diretamente ao rei, e não a jurisdições municipais.
} 
serviam como importantes entrepostos comerciais, os quais possuíam um papel de extrema relevância nas conexões entre os continentes europeu, asiático e africano. Nesse contexto, Maiorca tornou-se um reino independente de Aragão no período de 1276 até 1343, quando foi reincorporado por Pedro IV à Coroa aragonesa.

As disputas familiares travadas pela Coroa de Aragão e o Reino de Maiorca provêm da morte e respectiva partilha das terras de Jaime I de Aragão (1208-1276) entre seus dois filhos, Pedro (futuro Pedro III de Aragão) e Jaime (futuro Jaime II de Maiorca). Jaime herdou a região das Ilhas Baleares e regiões como Perpigan e Montpellier, cidades ricas que compunham a parte continental do reino, na fronteira com a França (NOGUEIRA, 2013, p. 100-113). Num primeiro momento, Jaime II de Maiorca e seus reinos foram submetidos a uma relação de vassalagem para com Pedro III de Aragão. Por meio dessa relação, ele exigiu que Maiorca contribuísse para a efetivação da conquista de Sardenha. Em razão disso, Jaime II recorreu à aljama Maiorquina, que colaborou, mais de uma vez, com aparatos de guerra, barcos e galeras em troca de concessões e privilégios.

Nesse contexto, o privilégio ${ }^{4}$ concedido aos judeus pode ser analisado como uma relação de poder entre aquele que concede (o rei) e os que recebem (alguns judeus que prestam serviços ao monarca). Em Maiorca, o vínculo do privilégio era observado comumente entre o rei e a comunidade judaica. Em meio a essa relação complexa, necessitava-se do outro (os judeus) próximo de si (o rei cristão), no entanto, somente até certa medida e por conta de questões políticas, exercitando, assim, um movimento de tolerância pragmática ${ }^{5}$ perante à comunidade judaica. Ao mesmo tempo em que um grupo necessita do outro dentro de prescrições específicas, essa situação também revela um processo que culminará na conversão forçada e expulsão de judeus de Maiorca no ano de 1391. Ou seja, o privilégio dos judeus seria o outro lado da moeda de uma tradição antijudaica.

A partir dessa complexa relação, observa-se que a comunidade judaica era um elemento-chave tanto para o desenvolvimento de Maiorca como para o desenvolvimento da Coroa Aragonesa; em outras palavras, a aljama é uma importante peça nesse jogo político. Pois, além de membros ativos no que se trata de comércio, os judeus expressavam uma demanda recorrente no setor administrativo, financeiro e na área médica, havendo uma proximidade desses com a Corte. Todavia, o contingente judaico que estava mais diretamente atrelado à Coroa era diminuto perante à população judaica que habitava a região (CHACÓN, 2004, p. 384).

O códice Pueyo é uma das fontes capazes de nos mostrar a maneira que se estabeleciam essas relações de privilégio. ${ }^{6}$ Por meio da leitura do códice, é possível

\footnotetext{
${ }^{4}$ Importante ressaltar que o termo "privilégio" utilizado nesse artigo está inserido num contexto medieval, possuindo um sentido jurídico, no qual havia uma relação entre duas partes, o que concede e o que recebe favores. Essa era uma relação de confiança e troca de favores, nesse caso, entre o rei e a comunidade judaica.

${ }^{5}$ Segundo Aline Dias da Silveira, na Corte de Alfonso X de Castela, onde intelectuais das três religiões se encontravam, o processo de tolerância poderia ser visto como uma quebra de fronteiras, uma concepção para além da tolerância pragmatista, uma vez que quando se é inserido nesse meio, há, além da necessidade, uma obrigação de contato, que faz com que de uma maneira ou de outra determinadas construções e pensamentos sejam colocados em dúvida diante do outro, do novo que está sendo conhecido e reconhecido. Para aprofundamento do tema, ver: Silveira, 2013.

${ }^{6} \mathrm{O}$ códice $P$ Pueyo é uma compilação de ornamentos que foram produzidos em relação à comunidade judaica entre 1328 e 1387 por notários do Reino de Maiorca. Para aprofundamento do tema ver: Fita; Llabres, 1900.
} 
perceber a necessidade que os novos governantes tinham de reafirmar privilégios concedidos por reis predecessores, embora, muitas vezes, esses também revogassem concessões já estabelecidas. Para além, em outros momentos, via-se como necessário reafirmar os privilégios concedidos em seus próprios reinados, o que pode apontar a não funcionalidade integral dessas concessões. Essas decorrências demonstram uma instabilidade política e econômica no que tange a governabilidade e as relações com os judeus e seus bairros.

Os privilégios poderiam ser concedidos tanto numa escala macro, com validade para toda a comunidade judaica, como observado no Códice Pueyo, bem como poderiam ser atribuídos a pessoas específicas. A familiaridade real era a denominação de um privilégio que aproximava os judeus da vida na Corte por fazerem serviços encomendados pela Coroa. Aqueles que detinham o título de familiar real geralmente possuíam destaque em seu ofício. É o caso de Cresques Abraham e sua família. Em 1368, aos 42 anos, o elaborador do Atlas Catalão se tornou familiar real do rei Pedro IV de Aragão e em 1381, ele recebe o mesmo título do príncipe João pela prestação de seus serviços. ${ }^{7}$

Cresques Abraham se tornou notório pela produção do Mapa Mundi, popularmente conhecido como Atlas Catalão. À sua época, a produção cartográfica em Maiorca era efervescente, ao passo que muitos judeus estavam envolvidos no desenvolvimento cartográfico, colaborando para o desenvolvimento e aprimoramento das cartas portulanas. ${ }^{8}$

O mapa que está inserido dentro do Atlas Catalão se distingue pela riqueza de detalhes e materiais utilizados, como a quantidade de cores, e a utilização de elementos metálicos, entre eles o ouro. Além de todo esse aparato artístico, constatamos que o Atlas Catalão também possui um caráter enciclopédico, pelas informações históricas, mitológicas, astronômicas, astrológicas, climáticas, entre tantas outras que estão inseridas na fonte. Assim, apesar de Riera i Sans (1978) argumentar que Cresques Abraham seria apenas um excelente iluminador atrelado à Corte Aragonesa, destacamos que a articulação de tantos conhecimentos em um único espaço criativo infere base intelectual consistente para a produção do Atlas Catalão. Nessa perspectiva, Katrin Kogman-Appel (2014) apresenta resquícios que evidenciam que o judeu maiorquino tinha conhecimentos de latim e hebraico, e destaca que comumente a educação de judeus sefarditas incluía o conhecimento do árabe.

Segundo o levantamento efetuado por Magali Nogueira (2013, p. 21; p. 190), boa parte das obras que constavam no acervo judaico em Maiorca foram produzidas a partir século XII entre judeus, cristãos e muçulmanos. Os inventários expostos por Nogueira em sua tese apresentam obras que muito provavelmente foram lidas por Cresques Abraham e estavam inseridas numa dinâmica de interconexões que possibilitaram a produção do Atlas Catalão. Essas relações são observadas por meio de um levantamento de textos que circulavam pela aljama de Maiorca, a exemplo de

\footnotetext{
${ }^{7}$ Existiam outros Códices de mesma natureza que o Códice Pueyo à época. Os privilégios concedidos a Cresques Abraham se localizam no Livro dos Privilégios e Franquias de Maiorca, que está localizado no Arquivo da Coroa de Aragão e que atualmente não possui acesso on-line. Contudo, Jaume e Riera desenvolveram um artigo onde apresentam excertos dessa fonte (SANS; RIERA, 1978).

${ }^{8} \mathrm{O}$ gênero cartográfico portulano surge a partir do século XIII nos arredores da bacia mediterrânica, sendo essa região representada de maneira muito semelhante ao real. Grande parte de exemplares remanescentes não possuem autoria ou datação conhecida. Mais informações em: Campbell, 1987, p. 371-463 e Nogueira; Biasi, 2015.
} 
dois inventários das bibliotecas dos judeus Mossé Almaterí e León Mosconis, sendo este último um médico, familiar real como Cresques Abraham. Após a morte de León Mosconis, parte de sua biblioteca foi leiloada e algumas dessas obras foram compradas por Cresques Abraham e outras, por seu filho, Jafudá Cresques. ${ }^{9}$

Não se pode afirmar com exatidão a natureza dos textos nos quais Cresques Abraham e seu filho tiveram contato. Entretanto, os levantamentos apresentados por Nogueira (2013, p. 133-135) apontam que havia uma interessante variedade de escritos que circulavam pela aljama, e algumas temáticas, como as de cunho filosófico/teológico e astronômico/astrológico, poderiam ser úteis aos produtores de nossa fonte. Além do mais, livros e textos circulavam por toda a comunidade judaica maiorquina, e ter conhecimento dessas bibliotecas e inventários abre larga possibilidade para pensar que existiam outras tantas e que envolviam a aljama. ${ }^{10}$

Ao observar as duas listas, encontramos uma obra distinta de Ptolomeu em cada um dos inventários dessas bibliotecas: o Almagesto e o Planisfério. O fato de pessoas na aljama possuírem esses textos pode explicar a influência direta de Ptolomeu no Atlas Catalão, uma vez que ele é uma das poucas autoridades que são diretamente citadas por Cresques Abraham na fonte.

Outro ponto de destaque se dá aos autores que escreviam sobre filosofia/ teologia. Em uma breve observação dos inventários, podemos perceber que os textos e autores citados são judeus (Ibn Gabirol, Isaac Israeli, Abraham bar Hyya, Abraham Ibn Ezra, etc.) e árabe-muçulmanos (Al-Battani, Al-Farabi, Averroes), além da presença de autores gregos (Aristóteles e Ptolomeu). Essas obras e pensadores estavam inseridos numa dinâmica de convergências e divergências entre as três religiões monoteístas. Carlos Escudé (2011) aponta que é possível enxergar aproximações entre os debates de filósofos do Cristianismo, Judaísmo e Islã ao mesmo tempo que dentro de cada uma dessas religiões havia debates que divergiam entre si.

Os agentes dessas articulações de pensamento não são citados diretamente no Atlas Catalão como no caso de Ptolomeu, mas aparecem pela visão cosmológica apresentada na fonte, o que reforça a ideia de que autores presentes nas bibliotecas da aljama provavelmente foram lidos por Cresques Abraham, uma vez que as sinagogas para as comunidades judaicas eram locais de oração, mas também de estudos, o que dá indícios do compartilhamento de ideias e materiais no aprofundamento desses estudos (ABULAFIA, 2002, p. 90).

Uma conexão que se pode fazer entre esses pensadores é a influência que sofreram do movimento neoplatônico, inspirado principalmente em Plotino (séc. III EC), mas também em Proclo (século $\vee$ EC), entre outros nomes. Esses neoplatônicos da

\footnotetext{
${ }^{9}$ A compra, em 1377, de livros por Cresques Abraham e seu filho, Jafudá, colaboram para nos fazer refletir acerca de seus interesses intelectuais. O primeiro citado compra seis livros: uma compilação do Haggadot; um livro de Adné Késef of Yosef Kaspí, sobre comentários místicos da Bíblia hebraica e os outros quatro livros comprados não possuem descrição. Já Jafudá comprou uma adaptação judaica do século XII sobre a lenda de Buda, uma cópia do Mispaté ha-mazalot, que era um trabalho astrológico muito popular escrito por Ibn Ezra (séc. XI). Acredita-se, ainda, que esses livros não foram comprados por alto valor, o que nos faz pensar que tais escritos não fossem muito raros ou preciosos para a época. Além do mais, essas obras provavelmente serviam para um desfrute intelectual coletivo na aljama. Para mais informações, ver: Sans; Riera, 1978, p. 11-12.

${ }^{10}$ Dos trabalhos encontrados nesses locais, aqueles que poderiam servir para Cresques Abraham e seu trabalho estão dispostos em Nogueira (2013, p.152-153).
} 
Antiguidade, séculos mais tarde, foram estudados pelos árabes, como Al-Farabi, Al-Battani e Averroes. Esses estudiosos, comentadores de Aristóteles e de neoplatônicos, também conhecidos como peripatéticos árabes, possuíam discussões filosóficas que em partes convergiam, e em outras divergiam entre si e que ocorreram nos debates públicos entre judeus e cristãos. A natureza divina de Deus, o conceito de emanação, a multiplicidade do Intelecto e a indivisibilidade do Uno foram temas constantes no pensamento desses autores (ESCUDÉ, 2011). O conceito de emanação divina neoplatônico propõe que Deus não criou tudo que existe, apesar de toda a existência prover dele. Assim como a luz provém do Sol, que não media uma vontade que ordene a radiação solar, a emanação divina não seria produto da vontade do Uno (entre os cristãos platônicos entendido como o deus abraâmico) (ESCUDÉ, 2011, p. 11).

No Atlas Catalão, Cresques Abraham aponta de formas variadas como o mundo surgiu, totalizando cinco maneiras. A quarta maneira é apresentada a seguir:

A quarta maneira é assim como uma coisa é feita de outra homem de homem, animal de animal, árvore de árvore - cada coisa nasce da semente da mesma linhagem, tal como está escrito (Atlas Catalão, Folio I, apud NOGUEIRA, 2013, p. 269-270). ${ }^{11}$

Essa concepção de criação do mundo, uma das cinco retratadas na fonte, aponta que uma coisa é feita a partir de outra, a partir de uma semente de mesma linhagem. Aqui, percebemos a influência neoplatônica, onde a simplicidade do Uno, por meio da emanação, gera o intelecto que é múltiplo e forma a alma do mundo. Nos escritos de Filon de Alexandria, judeu platônico do século I, o intelecto divino é arquetípico, pois molda o mundo a partir de sua imagem (FILON DE ALEXANDRIA, 2015).

Algo muito caro a esse pensamento medieval de influência neoplatônica é a alegoria, através da qual muitas camadas de sentido são sobrepostas e relacionadas. A alegoria antiga e medieval trazia consigo uma função didática, bem como pretendia conduzir a uma reflexão moral, metafísica ${ }^{12} \mathrm{e}$, até profética, na qual pela pré-figuração e figuração (AUERBACH, 1997) as temporalidades fluem para uma imagem. Por essa via alegórica, é possível conceber a transtemporalidade da imagem, ou seja, a sua qualidade de manifestar os diversos véus ou camadas temporais. A cartografia pertencia a esse universo alegórico de representar o mundo, tanto o grande mundo (macrocosmo), como o pequeno mundo (microcosmo), por isso o Atlas Catalão presta-se à leitura alegórica e iconológica que faremos a seguir.

Segundo John Brian Harley, teórico de História da Cartografia, os mapas são uma forma de linguagem muito abrangente e trazem consigo, inerentemente, toda a utilização política que contribui para a formação de um espaço socialmente construído. Além do mais, os mapas são produtos de um emaranhado de reflexões, observações e balanços científicos que dialogam diretamente com os estudos imagéticos e simbólicos da iconografia. Pela forma como mapas são constituídos a partir de seu contexto histórico, com suas imagens de relações políticas e de poder, torna-se arriscado analisá-los de maneira binária, como "verdadeiros e falsos", "exatos e inexatos", "objetivos e

\footnotetext{
${ }^{11}$ No original: "La quarta manera, es axi con 1 es fet daltre, axi con hom de home, bestia de bestia, arbre darbre, e cascu del sement de son linyatage es nat, axi con es scrit".

${ }^{12}$ Aqui utilizamos o sentido medieval de alegoria, como o é apresentado na obra de Umberto Eco (2010, p. 111-115).
} 
subjetivos", "literais e simbólicos", baseados na "integridade científica" ou marcados por uma "deformação ideológica". Harley (2009, p. 2-3) pontua o mapa como uma forma de linguagem que pode ser mais bem entendida na prática histórica, pois ela

não apenas nos ajuda a ver nos mapas imagens - espelhos servindo para intermediar diferentes visões do mundo, mas também nos leva a procurar dados empíricos sobre aspectos, tais como os códigos e o contexto da cartografia assim como sobre seu conteúdo tomado no sentido tradicional.

O mapa é linguagem imagética, historiograficamente inteligível, assim a aplicação de olhar iconográfico e iconológico pode nos trazer uma profundidade "não apenas para identificar um nível de significação 'superficial' ou literal, mas também um nível 'mais profundo', geralmente associado a uma dimensão simbólica do ato que consiste em emitir ou receber uma mensagem" (HARLEY, 2009, p. 3).

\title{
O HOMEM ZODIACAL COMO VETOR ENTRE O CÉU E A TERRA
}

Cresques, além de apresentar uma concepção neoplatônica para a criação do mundo no Atlas Catalão, como referido anteriormente, também utilizou o neoplatonismo para explicar as relações homem-natureza-cosmos, ao associar o corpo humano com o planeta Terra:

\begin{abstract}
A Terra se sustenta por si mesma tal como foi alimentada por Deus, ocupa o espaço de seu volume e está envolta por toda parte pelo Grande Mar, tal como está escrito: "O abismo é sua coberta como se fosse uma vestimenta". Por dentro, porém, é transpassada por veias de água igual ao corpo humano que é por veias de sangue. A secura da Terra é regada por estes veios de água e por isso em qualquer local onde se escava a terra é encontrado água (Atlas Catalão, Folio I, apud NOGUEIRA, 2013, p. 272)..$^{13}$
\end{abstract}

Nesse excerto, é comparado o complexo hídrico de nosso planeta às veias do corpo humano. Assim como o sangue é vital para a vida humana, a água promove a vida na Terra. De acordo com a visão de mundo dessa época, baseada em analogias da natureza e do cosmos (macrocosmos) com o corpo humano (microcosmos), o corpo pode ser entendido como um elo mediador que se comunica com o cosmos e com a natureza. É dessa forma que precisamos entender o homem zodiacal representado no Atlas Catalão, como um vetor que tem a forma do microcosmo, o corpo humano, e

\footnotetext{
${ }^{13}$ No original: "La terra fundada es sobre la su fermetat, axi con de Deu fo alementada, occupant lo terme de la sua quantitat; e en torn e en gir es environada e cenyida en lo lim de la Gran mar, axi com es scrit : Lo abis es cobriment de aquella, axi con avestiment. De dintre empero axi es trespassada per passaments daygues, con es lo cors per venes de sanch. Per los quals passaments daygues la sequedat de la terra es regada, perque en tot loch que la terra es cavada se atroba aygua".
} 
a substância do macrocosmo, as esferas celestes, ou seja, uma alegoria pronta para desvendar e estabelecer a reunião da parte com o todo.

O tema do homem zodiacal, é também trazido no texto de uma conferência de Aby Warburg em homenagem a Franz Boll:

\begin{abstract}
Frente ao mundo estelar, o reduzido número de astros conhecidos pela astronomia (o telescópio ainda não fora inventado) facilitou a ideia, no fundo sublime, de que o ser humano deve ser visto como um pequeno cosmos que mantém relações totalmente diretas com o mundo astral. [...] Desponta como símbolo prevalente por séculos o assim chamado homem zodiacal (WARBURG, 2015, p. 289-348).
\end{abstract}

A relação entre o micro e macrocosmo, citada por Warburg, tivera seu fundamento filosófico no neoplatônico medieval, na esteira do neoplatonismo tardo-antigo que permaneceu vivo, como que em pós-vida (nachleben) nas referências e no movimento das interpretações das três culturas monoteístas abraâmicas medievais: Cristianismo, Islã e Judaísmo (ESCUDÉ, 2011). Assim, como medievalistas, ao utilizarmos discussões e métodos da iconologia para desenvolvermos nossa análise, nosso objetivo orienta-se, principalmente, pela busca do entendimento sobre o movimento do saber no período medieval, pelo caminho mais próximo de uma ciência da cultura (Kulturwissenschaft) como reivindicou Aby Warburg.

Quando Warburg usa o termo nachleben (pós-vida) é no sentido da ressignificação dos elementos pagãos/antigos nas imagens renascentistas que ele estudou. Segundo a compreensão deste estudioso, os elementos para essa ressignificação seriam buscados em uma memória comum, construída a partir de experiências extáticas na história da humanidade. Dessa forma, o conceito de nachleben está relacionado com o que Warburg chamou de imagem mnemônica nos estados dinâmicos comuns (Erinnerungsbild an allgemeine dynamische Zustände). Em sua terceira tese ele afirma:

III. A perceptível imagem mnemônica nos estados dinâmicos comuns na nova impressão, será, posteriormente, projetada na obra de arte de forma inconsciente, como esboço idealizador (WARBURG, 1932, p. 58, tradução nossa). ${ }^{14}$

Interpretamos a ideia de estados dinâmicos comuns (allgemeine dynamische Zustände) expressa nesse trecho, como estados para onde confluem diversas temporalidades ao ponto de instaurar o transcronismo da imagem mnemônica, só que sua projeção na obra de arte não é inconsciente, mas uma "substituição consciente", como depois corrigiu o próprio Warburg (2015, p. 87). Por essa perspectiva, a análise imagética do Atlas Catalão do século XIV movimenta-nos para outros espaços e temporalidades, bem mais além, na busca das correntes e caminhos das fontes e seus significados. Analisaremos tanto os significados gerais, como os mais específicos da imagem do homem zodiacal em relação a outras do mesmo sistema simbólico e/ ou alegórico.

\footnotetext{
${ }^{14}$ No original: "III. Das den neuen Eindruck apperzipierende Erinnerungsbild an allgemeine dynamische Zustände wird später beim Kunstwerk unbewusst als idealisierender Umriss projektiert".
} 
Quando Aby Warburg disse que "o ser humano deve ser visto como um pequeno cosmos que mantém relações totalmente diretas com o mundo astral", ele se referia a uma visão de mundo que fora expressa em diferentes manifestações da experiência humana da temporalidade medieval. No âmago da relação entre o ser humano e o mundo, estava a chave do Imago mundi, ou seja, todo o universo se faz presente em escala menor e na mesma proporção áurea no corpo humano. Com essa chave, tratados de medicina, astronomia, astrologia, música, matemática, política e de todas as outras formas de conhecimento da época foram escritos (SILVEIRA, 2012, p. 151-166).

Essa chave também é necessária para entendermos o homem zodiacal do Atlas Catalão. No Folio I, parte B3, Cresques Abraham refere-se a Ptolomeu, provavelmente, Claudius Ptolomeu, nascido no Egito do século II da era cristã e que escreveu sobre astronomia/astrologia, cartografia, matemática e música. Sua principal obra de astrologia foi traduzida do árabe para o castelhano na corte de Afonso X de Castela no século XIII, conhecida como Tetrabliblos (MACHADO, 2007). Junto à figura do homem zodiacal no Folio I, parte B3 encontramos o seguinte o trecho da obra:

Disse Ptolomeu: "Guarda-te de não ferir o corpo com ferro nem fazer sangria enquanto a Lua se encontre no signo que rege $o$ membro". Então, se queres saber, a qualquer momento, em que signo se encontra a Lua, porque necessitais uma medicina ou tens que sangrar ou fazer alguma coisa, ainda que já tenhamos mostrado mais acima, na roda anterior, aqui o encontras mais claro. Fareis assim: contais quantos dias lunares temos e quantos dias que tenham passado, observe na tábua abaixo; observe o número da margem em que há o dia que estareis e põe aí o dedo, depois percorra a tábua do mês: o ponto onde cair diretamente é ali onde se encontra a Lua, naquele signo. Sabeis que os doze signos estão repartidos por todo o corpo, como podemos ver nesta figura: Áries na cabeça, Touro no pescoço, Gêmeos nos braços e assim até os pés (Atlas Catalão, Folio I, apud NOGUEIRA, 2013. p. 268, grifo da autora). ${ }^{15}$

Em correspondência com o esse trecho e com a tabela sequente a ele, cada parte da figura ao lado do texto (o homem zodiacal) tem escrito sobre si o nome da constelação zodiacal correspondente: cabeça: Áries; pescoço: Touro; braços: Gêmeos; peito: Câncer; ventre: Virgem-Libra, genitais: Escorpião; nádegas: Sagitário; coxas: Capricórnio; panturrilhas: Aquário; pés: Peixes:

\footnotetext{
${ }^{15}$ No original: "Diu Tolomeu: 'guarda`t que no tochs en ta persona ab ferra ne segnar, mentra que la luna és en aquel signe qui es sobra aquel membre. 'Adonch' si vol saber totz jorns en qual signe és la luna, si obs o avets [permedicina] [o per] sagnar ho d'altra manera, jatsia que us [havem] mostrat pus sobr[...] en la roda pasada, però assí ho trobareu pus clar e faretz-ho ayxi: omptatz quants jorns tenin de la Luna, e aytants jorns quants n'aurà passatz guardats en aquesta taulla devalt scrita, e guarda lo nombra del màrgen (en què) en què serà lo jorn en què sarets, e posa aquí lo dit; puys davalla per la taula, del mês: enaquí un caurà dret lo dit aquí es la Luna en aquell signe. E sapiatz que los XII. signes són conpertitz per toda la persona assí con o podets veer en aquesta figura; Aires per lo cap, Tauros per lo col, Geminis per los brasos, fin als peu'".
} 
Figura 1 - O homem zodiacal e a tabela de correspondência de signos zodiacais com as partes do corpo Humano

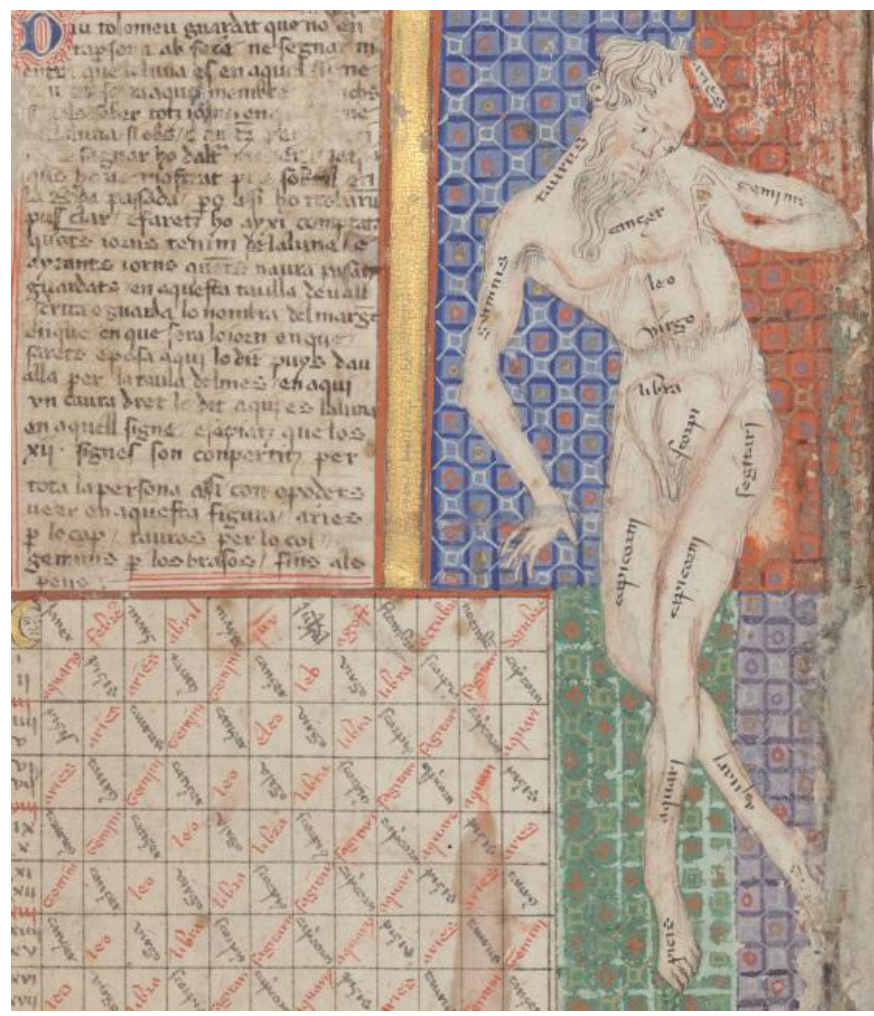

Fonte: Recorte do Manuscrito Espagnol 30, Folio I. Disponível em: https://gallica.bnf.fr/ ark:/12148/btv1b55002481n?rk=21459;2.

A relação do zodíaco com partes do corpo e os quatro elementos (representados nas quatro cores ao fundo da figura) é retomada no Folio II, sobre o calendário, a exemplo desses dois trechos:

Aries é quente e seco e da natureza do fogo, é casa de Marte, é de signo masculino. Com a Lua neste signo é bom para sangrias e aplicar medicinas, porém não se há de fazer medicina na cabeça. Touro é frio e seco, da natureza da Terra, é casa de Vênus, é masculino. Com a Lua em Touro não é bom para sangrias e nem tampouco é bom para aplicar medicina nem fazer medicinas no pescoço (Atlas Catalão, Folio I, apud NOGUEIRA, 2013, p. 284, grifo da autora).$^{16}$

Essas correspondências encontravam-se em variadas fontes medievais, não só naquelas que faziam referência à obra de Ptolomeu, pois os textos compilados e utilizados na Idade Média possuíam origens e procedências diversas. As correspondências entre o micro e macrocosmo nos remetem à reunião de saberes milenares desde as

\footnotetext{
${ }^{16}$ No original: "Aries [és] caut e sech e de natura de foch e caza de Març e signe meschulí. La Luna em aquest signe és bona sagnia e pendre medecina, e no fazzes medeçina al cap. Taurus és fret e sech, de natura de terra e és caza de Venus e maschulí. La Luna en Taurus no és bona sagnia ne pendre medeçina ne fer medeçina al choll".
} 
tábuas mesopotâmicas do século VII antes da era cristã Enuma Anu Enlil (BARTON, 1994) que são difundidas e reelaboradas no período helenístico, até às tábuas astrológicas (ALFONSO, 1984) do rei Afonso X de Castela do século XIII. O platonismo foi o fundamento que deu coesão filosófica para essas correspondências na relação intrínseca entre o microcosmo e o macrocosmo no ocidente. No caso medieval, sua relação é maior com o neoplatonismo desenvolvido a partir do século III da era cristã. O macrocosmo platônico/ptolomaico é dividido em esferas planetárias concêntricas, que são vistas como potências do Intelecto emanado do Uno, o princípio de todas as coisas. As virtudes dessas esferas fluem até a esfera lunar (por isso a importância da Lua em todas essas obras medievais astromágicas), que, como um prisma, faz fluir as virtudes planetárias para a esfera terrestre, também chamada de sublunar, influenciando tudo que está sobre e sob a Terra. Como podemos ver representado no segundo fólio do Atlas Catalão, onde a esfera lunar é representada com as fases lunares.

Figura 2 - Macrocosmo

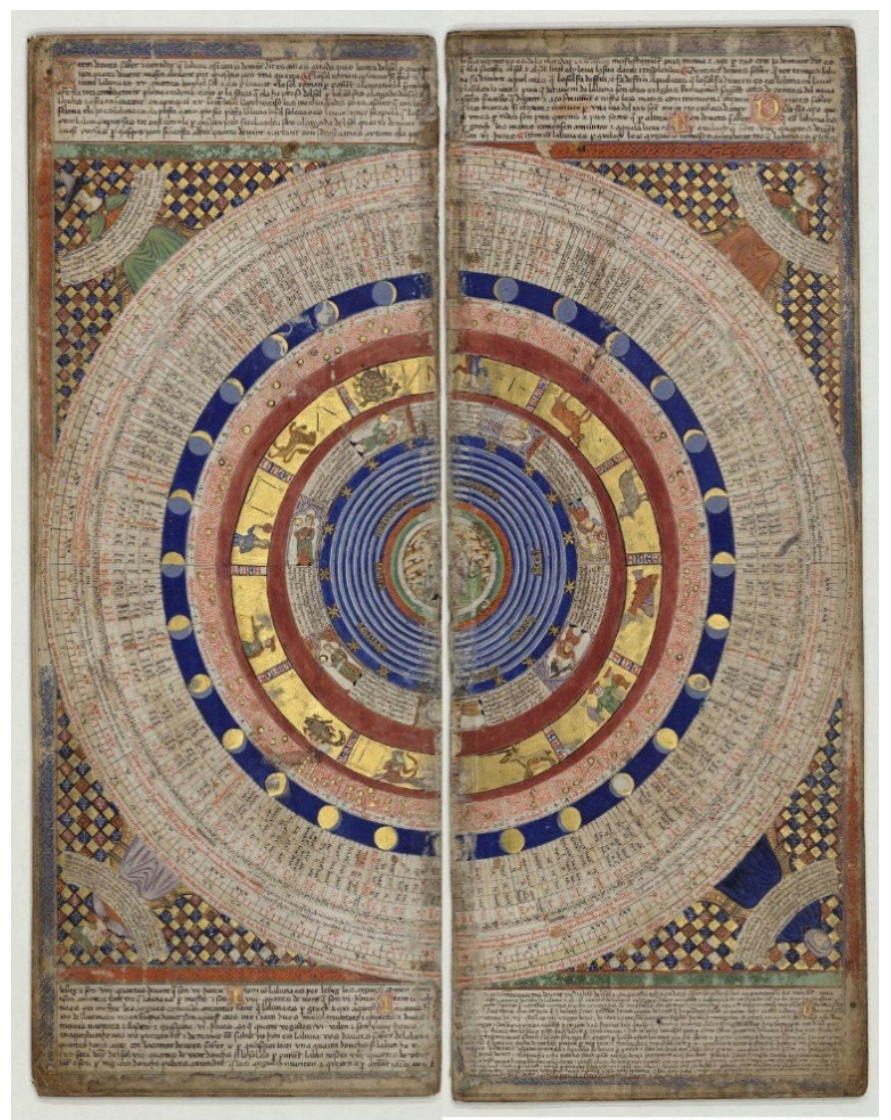

Fonte: Recorte do Manuscrito Espagnol 30, Folio I. Disponível em: https://gallica.bnf.fr/ ark:/12148/btv1b55002481n?rk=21459;2.

Com as rotas de comércio da Antiguidade e do Medievo, esses saberes, por meio de textos e oralidades, percorreram caminhos do norte da África para Europa e Índia, da Índia para a Pérsia e novamente para o Mediterrâneo, num movimento de traduções, acumulações, interpretações e busca de uma súmula para o saber. Derivada deste movimento, a confluência cultural na Península Ibérica medieval forjou obras como o Gayat al-Hakim, também conhecido como Picatrix (PICATRIX, 1962, 1986; BOUDET; CAIOZZO; WEILL-PAROT, 2011) que influenciou imensamente as obras chamadas 
de renascentistas. Essa obra escrita na Península Ibérica muçulmana do século XI e depois traduzida por judeus na Corte do rei cristão Afonso X de Castela, refere-se a fontes indianas, gregas, persa, mesopotâmicas, egípcias e romanas em seu texto, de forma que o autor relata no prólogo que utilizou mais de 200 obras para constituí-la (STUCKRAD, 2011, p. 331-340). Por ser uma amálgama medieval do movimento do saber milenar, parece-nos interessante trazer aqui o princípio da relação entre micro e macrocosmo manifesta no Gayat al-Hakim:

Deus, Aquele que trouxe as coisas para a existência, as quais não existiam antes. Aquele que renovou a criação e lhes concedeu o dom da graça. Ele é aquele que determina e cria todas as coisas (PICATRIX, 1962, p. 1 §1-9, tradução nossa). ${ }^{17}$

Deus fez do ser humano o guardião de sua sabedoria e uma expressão de si mesmo e de toda sua criação, o fez recebedor de sua inspiração e receptáculo de suas ciências, seu arauto, um broto e uma cópia do macrocosmo, de forma que ele (o ser humano) reúne em sua construção e constituição todos os entendimentos (PICATRIX, 1962, p. $41 \S 13-19$, tradução nossa). ${ }^{18}$ A força formuladora $e$ as sete forças pneumáticas, que correspondem aos pneumas dos sete planetas, são as forças sensíveis, das quais dependem a perfeição do ser humano e a conclusão perfeita de suas atividades (PICATRIX, 1962, p. $45 \S$ 4-10, tradução nossa). ${ }^{19}$

A passagem citada "Deus fez do ser humano [...] um broto e uma cópia do macrocosmo, de forma que ele (o ser humano) reúne em sua construção e constituição todos os entendimentos" pode explicar a importância do corpo humano zodiacal no Mapa Mundi de Cresques. Para a compreensão do espaço do mundo maior (macrocosmo), figurado em outras folhas do Atlas, é necessário entender a relação deste com o mundo menor (microcosmo), o corpo humano. Pois, o corpo humano é o Imago Dei, a imagem de Deus (BÍBLIA DE JERUSALÉM, 2010, Gn 1, 27), e, por tanto, um espelho do mundo também. Isso fica mais evidente, quando buscamos, na própria fonte, as maneiras de como esse mundo foi criado, as quais, como mencionado no texto citado, segundo Cresques, são cinco. A segunda maneira da criação é descrita assim: "está escrito que do mesmo modo e exemplo do arquétipo e da sensibilidade a matéria do mundo foi criada" (Atlas Catalão, Folio I, apud NOGUEIRA, 2013, p. 270). ${ }^{20}$ A palavra archetipi utilizada por Cresques Abraham indica sua proximidade com os escritos do

\footnotetext{
17 No original: "Gott, ( ) der die Dinge in die Existenz herausgeführt hat, nachdem sie zuvor nicht existierten, der die Geschöpfe neu hervorgebracht und ihnen ihre Gnadengaben zugewiesen hat. Er ist der Bestimmer und Neuhervorbringer alles Seienden".

${ }^{18}$ No original: "Gott hat inn zum Schatzmeister seiner Weisheit und zu einem Ausdruck seiner selbst und all seiner Geschöpfe gemacht, zum Empfänger für seine Inspirationen und zum Gefäß seiner Wissenschaften und Verkünder für sich, zu einem Sproß und einer Kopie des Makrokosmos, so dass er in seinem Bau und seiner Zusammensetzung alle Begriffe desselben vereinigt".

${ }^{19}$ No original: "( ) die formende Kraft und sieben pneumatische Kräfte, die den Pneumata der sieben Planeten entsprechen, sind die empfindenden Kräfte, auf denen die Vollkommenheit des Menschen und die Vollendung seiner Tätigkeiten beruht ( )".

${ }^{20}$ No original: "La segona manera es scrita que amanera e eximpli de archetipi e de sensible la materia del mon es creada, axi com es escrit. Aquell qui esta per/durablament crea totes coses/ ensemps".
} 
filósofo judeu platônico Filon de Alexandria (séc. I), que propôs a interpretação alegórica da Torah em diálogo com a filosofia platônica, identificando a inteligência divina como um arquétipo, um modelo ideal e primordial, que moldaria todas as coisas a sua imagem (MORAES, 2017, p. 113-117). A alegorese de Filon de Alexandria influenciou fortemente a exegese bíblica judaica e cristã tardo-antiga e medieval, assim a presença do termo archetipi no Atlas Catalão independe da possibilidade de Cresques ter ou não lido diretamente Filon, pois constituía uma corrente consolidada de interpretação. O platonismo e seu desdobramento neoplatônico tardo-antigo contribuíram para o desenvolvimento da mística judaica, figurada nos ensinamentos da kabbalah (הלבק), ou cabala, como ficou popularizada na língua portuguesa. Aqui, é importante considerar que um dos livros mais importantes para a escola cabalística medieval e moderna é o Zohar (o esplendor) que surgiu pela primeira vez na Espanha do século XIII, ambiente e contexto de Cresques Abraham.

Nos ensinamentos da cabala, "Os cabalistas procuram explicar o mistério do mundo como reflexo do mistério da vida divina como também o fizeram os gnósticos. Assim, para a cabala, cada indivíduo é totalidade" (CAMPANI, 2011, p. 5-6). Também pela perspectiva da cabala, o corpo seria compreendido como Imago Mundi, da mesma forma, como denominou Cresques no seu Mapa Mundi. Por essa via, o corpo é a medida e o vetor para compreender o que ainda não foi conhecido. Para complementar esse pensamento, podemos trazer um elemento mais específico da imagem: o homem zodiacal de Cresques é uma representação do corpo judeu. Acreditamos que elementos da mística judaica, dão especificidade à expressão do homem zodiacal de Cresques Abraham, ao mesmo tempo, enfatizam a relação entre o Imago Mundi humano e macrocosmo divino.

A figura do Atlas Catalão apresenta um homem nu de idade madura, expressa pela barba, pela calvície e por pelos no corpo. Apesar da maturidade, o corpo ainda apresenta os músculos bem formados, o que poderia lhe atribuir uma idade entre $30 \mathrm{e}$ 50 anos. Seu corpo está em movimento, indicado pelas posições dos pés e dos braços, sendo que o braço esquerdo parece indicar um movimento ascendente e o braço direito um movimento descendente. A cabeça inclina-se em direção aos pés, mas o olhar está direcionado para a mão esquerda. O espaço simbólico em que esse corpo está colocado é o plano dos quatro elementos representados nos quatro retângulos atrás dele. O pé esquerdo toca a terra, o retângulo verde, o pé direito toca a água, o retângulo azul-claro, a mão direita toca o ar, o retângulo azul-escuro, e a mão esquerda toca o fogo.

A nudez do homem é uma referência ao estado original de pureza de espírito. A barba não indica só a idade madura, mas uma possível referência ao Antigo Testamento e à tradição judaica, como expressa em Levítico 19, 27: "não cortareis a extremidade da vossa cabeleira em redondo e não danificarás a extremidade da tua barba" (BÍBLIA DE JERUSALÉM, 2010, Lv 19, 27). Vejamos esse e outros elementos presentes na iluminura de um manuscrito sefardita catalão que foi elaborado no mesmo contexto e

\footnotetext{
21 "A palavra 'cabala' (הלבק) significa literalmente "tradição" em hebraico. A cabala é a tradição das coisas divinas, o conhecimento sagrado (a gnosis), o misticismo judaico, a suma do judaísmo. As raízes da cabala podem ser encontradas na literatura judaica da Maase Bereshit e Maase Merkabá" (Apud CAMPANI, 2011, p. 3).
} 
época que o Atlas Catalão, conhecido como o Haggadah ${ }^{22}$ de Barcelona, encontrado na coleção da biblioteca de John Rylands em Manchester:

Figura 3 - Êxodo - Manuscrito Haggadah sefardita catalão do século XIV

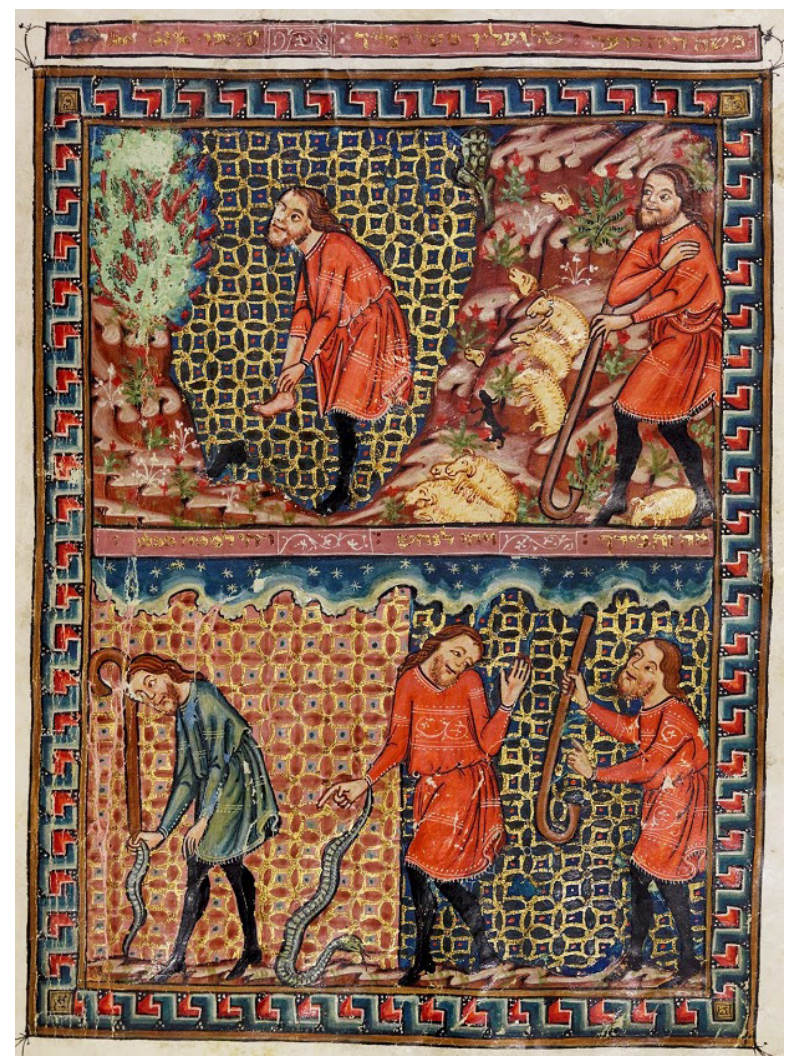

Fonte: John Rylands Library Collection, Manchester/UK. Disponível em: https:// chiccmanchester.wordpress.com/2012/01/04/rylands-haggadah-hebrew-ms-6/.

$\mathrm{Na}$ iluminura da Figura 3, Moisés está representado com barba, como ocorre na maioria das representações medievais de judeus. No entanto, em outras imagens do homem zodiacal, o corpo também é representado com barba em referência à Jesus. Qual seria, então, a especificidade da representação do homem zodiacal no Atlas Catalão que o colocaria na tradição dos judeus ibéricos, os sefarditas? O gesto corporal e a tradição cabalística da Península Ibérica, como pretendemos evidenciar adiante.

Seguindo com nossa análise iconológica, evidenciamos elementos recorrentes entre a iluminura do Haggadah sefardita e o homem zodiacal do Atlas Catalão. A iluminura apresenta dois momentos do Livro do Éxodo no Pentateuco, na passagem em que Moisés (em vermelho) sobe o Monte Sinai e escuta a voz de Javeh diante da sarça ardente (BÍBLIA DE JERUSALÉM, 2010, Ex. 3, 1-6) (primeiro quadro de cima na iluminura da Figura 3). No segundo quadro da iluminura, encontra-se representada a passagem em que Moisés a pedido de Javeh molda uma serpente de bronze e a

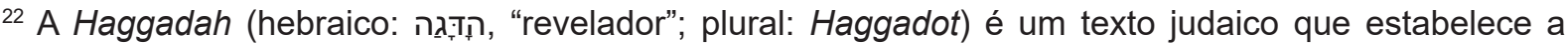
ordem do Seder da Páscoa. Ler a Hagadá à mesa do Seder é um cumprimento da mitzvá a cada judeu para "contar a seu filho" a libertação judaica da escravidão no Egito, conforme descrito no Livro do Êxodo na Torá (BARCELONA HAGGADOT, 2015, p. 17).
} 
coloca em uma haste (BÍBLIA DE JERUSALÉM, 2010, Nm. 21, 4-9). Gostaríamos de focar a atenção para a representação de Moisés ao centro no quadro de baixo dessa imagem. Nessa representação, o movimento é o mesmo do homem zodiacal no Atlas Catalão: a perna esquerda cruza a direita, a mão direita aponta para a terra, a esquerda para o céu e a cabeça olha para a mão esquerda. Essa figura de Moisés está centrada no manuscrito como que uma imagem mediadora entre o os tempos representados na iluminura, da direita para a esquerda, passado, presente e futuro. O gesto com as mãos o coloca também como mediador entre os espaços celeste e terreno, figurando a primeira letra do alfabeto hebraico, Aleph. Esse é, possivelmente, o elemento mais importante para entendermos a imagem do homem zodiacal no Atlas Catalão.

A letra Aleph ( $(\boldsymbol{)})$ performatizada no corpo do homem zodiacal e no Moisés "mediador" evidência a expressão judaica do platonismo medieval na Cabala. Segundo a obra Sefer Yezirah (CAMPANI, 2011, p. 11), um dos livros utilizados nos fundamentos da Cabala, Aleph pertence às três letras primordiais, chamadas de as Três Mães, que também estão relacionadas com os elementos, sendo que Aleph é o ar entre a água que desce, a letra Men (מ), e o fogo que sobe, a letra Shin (ש). No Sefer Yezirah encontramos:

3:3 Três Mães, Álef, Mén e Shin, no mundo são Ar, Água e Fogo. Os céus foram, primeiro, criados do Fogo, a terra foi criada da Água, e o Ar é o mediador entre o Fogo e a Água (CAMPANI, 2011, p. 161).

3:6 Ele fez Álef reinar sobre o vento e colocou uma coroa nela, e Ele combinou elas [as letras] uma com outra. Ele selou com elas Ar no Mundo, Temperado no Ano e o Corpo na Alma: Macho com Álef, Mén e Shin e a fêmea com o Álef, Shin e Mén (CAMPANI, 2011, p. 168).

Em relação com o excerto cabalístico citado, encontramos no texto das folhas astrológicas do Atlas Catalão:

Os elementos vamos dizer são como ligamentos de ilé e ilé é matéria. Os elementos, que compõem todas as coisas que existem no mundo, são quatro: fogo, ar, água e terra. Estão dispostos em forma de círculo e se resolvem uns nos outros: ou seja, o fogo em ar, o ar em água e a água em terra, a terra também se torna em água, água em ar e o ar em fogo se transformam (NOGUEIRA, 2013, p. 271). ${ }^{23}$

A presença deste pensamento no Sefer Yezirah e no Atlas Catalão não é uma surpresa, pois o postulado dos quatro elementos primordiais foi comum entre as culturas ocidentais e orientais, do Oriente Próximo à Índia, por mais de 20 séculos. ${ }^{24}$ Assim, o

\footnotetext{
${ }^{23}$ No original: "Los elaments volen aytant dir com ligament de ile; ile es matéria. Empero los elaments del mon son. IV. de les quals totes les coses del mon son; so es saber: foch, aer, aygua e terra, los quals son a manera. de cercle, e se resolven en si mateis: car lo foch en aer, lo aer en aygua, la aygua en terra se convertexen : hoc encara: la terra en aygua, la aygua en aer, lo aer en foch se muden".

${ }^{24}$ Os quatro elementos sutis como fundamentos da matéria, ou arché, surgem nos escritos dos pré-socráticos com Empédocles de Agrigento (séc. V a.e.c).
} 
que nos chama a atenção não é a semelhança dos textos, mas a figuração alegórica da letra do alfabeto hebraico Aleph como corpo humano, evidenciando, através deste detalhe, a tradição cabalística medieval na compreensão do espaço.

O movimento performatizado nas imagens comparadas colocam o corpo humano como mediador entre as esferas celestes (os céus) e a terra. Esse corpo passa de afetado pelos astros a vetor de suas influências, bem como também vetor dos elementos (fogo, ar e água) que formariam a substância da matéria. Através do braço esquerdo, flui o elemento fogo que sobe aos céus e, através do braço direito, flui o elemento água que desce formando a terra. Aleph, o ar, está performatizado no corpo, e é o mediador que reúne as letras mães. Correspondente ao número 1, Aleph simboliza a unidade humana com o todo, o Uno.

\section{CONSIDERAÇÕES FINAIS}

O gesto do homem zodiacal de Cresques, sua dinâmica e seu movimento, bem como o movimento fluido e sutil dos elementos, que a princípio poderia parecer uma simples representação humana, traz a potência de toda a obra em sua configuração alegórica. Lembramos novamente Warburg que percebeu a potência do gesto e do movimento nas imagens em suas teses, onde escreve:

A energia da disposição poética é, para nós, tão intensamente palpável, porque a energia do contexto real (que historicamente relutamos tanto em perceber) comunica-se conosco justamente na energia do movimento de renúncia que atua idealizando e recobrindo o real de enigmas (WARBURG, 2015, p. 86).

É no movimento expresso na imagem que o entendimento de Cresques sobre o mundo se revela para além do texto do manuscrito. Neste artigo, tentamos desvendar alguns enigmas deste homem zodiacal performático. Do texto à imagem do Atlas Catalão, da alegoria à revelação, o homem micro-macrocosmo zodiacal é desvelado como a chave e o vetor para o entendimento das próximas folhas que seguem no manuscrito.

O Mapa Mundi de Abraham de Cresques também é, como o corpo humano, imago dei. Assim, se deveria entender os rios, os mares e a água sob a terra como o sangue que corre pelo corpo: assim como o sangue sofre a pressão baixa e alta, assim também são as marés. Os reinos sobre a terra possuem seu correspondente no plano zodiacal, bem como as partes do corpo humano. E, entre a esfera terrestre e as esferas supralunares está o mediador, o homem- $\kappa$, que figura em sua performance a correspondência, o movimento e a totalidade constituída pela terra e o céu.

Por este caminho, o Atlas Catalão constitui uma obra imagética de teor enciclopédico, trazendo um conjunto de saberes de lugares distintos e de temas múltiplos, que não ficam apenas dentro de um "ramo cartográfico", mas também astronômico, astrológico, que pensava a natureza e a sua relação com o homem (HOLLAND, 2010). O poder e a alegoria estão intrinsecamente vinculados, uma vez que são utilizadas alegorias, símbolos e linguagem imagética para a construção de discursos de poder que se fortalecem por meio dos mapas, em sua função política, patrimonial e enciclopédica. Dessa forma, é de suma importância, 
encarar os mapas como sistemas de signos incomparáveis, nos quais os códigos podem ser ao mesmo tempo imagéticos, linguísticos, numéricos e temporais, e como uma forma de saber espacial. Não é difícil proceder generalizações sobre o papel mediador dos mapas no pensamento ou na ação política e de reter seus efeitos em termos de poder (HARLEY, 2009, p. 19-20).

O Atlas Catalão foi dado de presente em 1381 ao jovem rei da França, Carlos VI, por João de Aragão, que era ainda infante na ocasião. Um presente valioso, digno de um rei, e que poderia servir para instrumentalizar uma aliança entre os dois reinos. Ao mesmo tempo, o Atlas constitui um patrimônio das culturas mediterrâneas por confluir e configurar elementos do judaísmo, islã e cristianismo, além elementos astronômicos milenares.

Dentro da compreensão de mundo medieval, a qual transcende as interpretações canônicas cristãs, a percepção neoplatônica de correspondência entre o microcosmo e o macrocosmo foi a lente para representar e compreender o mundo. Por isso, para entender o Atlas Catalão em sua complexidade e completude é necessário percebê-lo como expressão da forma de entender o mundo pelos medievais e, em especial, pelo judeu sefardita.

\section{REFERÊNCIAS}

ABULAFIA, David. A Mediterranean emporium: the Catalan kingdom of Majorca. Cambridge: Cambridge University Press, 2002.

ABULAFIA, David S. H.; BATES, David. The Western Mediterranean Kingdoms: The Struggle for Dominion, 1200-1500. London: Routledge, 2014.

ALFONSO EL SABIO. Les Tables Alphonsines. Avec les canons de Jean de Saxe (Joannes Saxoniensis) lat. u. franz. Trad. por H Emmanuel Poulle. Paris: Ed. du Centre national de la recherche,1984.

AUERBACH, Erich. Figura. São Paulo: Editora Ática, 1997.

BARCELONA HAGGADOT. The Jewish Splendour of Catalan Gothic. Barcelona: Museu D'História de Barcelona, 2015.

BARTON, T. Ancient astrology. London: Routledge, 1994.

BÍBLIA DE JERUSALÉM. 6a impressão. São Paulo: Paulus., 2010.

BOUDET, Jean-Patrice; CAIOZZO, Anna; WEILL-PAROT, Nicolas (ed.). Images et magie: Picatrix entre Orient et Occident. Paris: Honore Champion, 2011.

CAMPANI, Carlos A. P. Fundamentos da Cabala: Sefer Yetsirá. Edição revisada e ampliada. Pelotas: Editora Universitária da UFPEL, 2011. 
CAMPBELL, Tony. Portolan Charts from the Late Thirteenth Century to 1500. In: HARLEY, John B.; WOODWARD, David. The History of Cartography. v.1, pt. 3, cap. 19. Chicago: press Uchicago, 1987.

CHACÓN, Jorge Maíz. Política, economía y fiscalización de un espacio urbano: el establecimiento de la aljama de los judíos en la Mallorca cristiana. Espacio Tiempo y Forma, Serie III, Historia Medieval, Madrid, n. 17, 2004.

CRESQUES ABRAHAM. Atlas de cartes marines, dit Atlas catalan Manuscrito Espagnol 30. Biblioteca Nacional da França. Disponível em: https://gallica.bnf.fr/ ark:/12148/btv1b55002481n?rk=21459;2. Acesso em 3 set. 2019.

ECO, Umberto. Arte e beleza na estética medieval. Tradução de Mario Sabino Filho. Rio de Janeiro: Record, 2010.

ESCUDÉ, Carlos. Neoplatonismo y pluralismo filosófico medieval: un enfoque politológico. Serie Documentos de Trabajo, $n^{\circ} 475$. Universidad del Centro de Estudios Macroeconómicos de Argentina (UCEMA): Buenos Aires, 2011. Disponível em: https://www.econstor.eu/bitstream/10419/84423/1/684924749.pdf. Acesso em 9 set. 2020.

EXXODO. John Rylands Library Collection, século, XIV. Disponível em: https:// chiccmanchester.wordpress.com/2012/01/04/rylands-haggadah-hebrew-ms-6/. Acesso em: 3 set. 2019.

FILON DE ALEXANDRIA. Da criação do mundo e outros escritos. Trad. Luíza Monteiro Dutra. São Paulo: Filocalia, 2015.

FITA, Fidel; LLABRES, Gabriel. Privilegios de los hebreos mallorquines en el Códice Pueyo: Segundo periodo, sección primera. Tomo 36, p. 122-148, 1900. Disponível em: http://www.cervantesvirtual.com/nd/ark:/59851/bmc377q6. Acesso em: 8 set. 2020.

HARLEY, John Brian. Mapas, saber e poder. Confins [Online], São Paulo, n. 5, p. 1-24, 2009. Disponível em: https://journals.openedition.org/ confins/5724?lang=pt\#citedby. Acesso em: 8 set. 2020.

HOLLAND, Kathleen. Looking Beyond: Globalization in the Catalan Atlas of the Fourteenth Century. Fifth Annual Graduate Student Symposium: Language and Communication in the Middle Ages: the Visual, the Lyrical, the Liturgical, the Legal, the Dramatic, the Kinetic, the Spatial, Translation, Lingua Franca, and Literacy, University of North Texas, Denton, 4-5 February, 48p., 2010.

KOGMAN-APPEL, Katrin. Elisha ben Abraham, Known as Cresques: Scribe, Illuminator, and Mapmaker in Fourteenth-Century Mallorca. Ars Judaica. Tel Aviv, v. 10, p. 27-36, 2014. 
MACHADO, Cristina Amorim. O tetrabiblos na História: um percurso de traduções da obra astrológica de Ptolomeu. $9^{\circ}$ Simpósio Nacional de Astrologia do SINARJ e no $2^{\circ}$. Congresso Internacional de Tradução e Interpretação da ABRATES, ambos realizados no segundo semestre de 2007. Disponível em: https://www.maxwell.vrac. puc-rio.br/12613/12613.PDF. Acesso: 27 fev. 2019.

MORAES, Dax. Transcultural. O logos em Fílon de Alexandria [recurso eletrônico]: a fronteira entre o pensamento grego e o pensamento cristão nas origens da teologia bíblica. Natal: EDUFRN, 2017.

NOGUEIRA, Magali Gomes. O manuscrito Espagnol 30 e a Família do judeu Cresques Abraham: um estudo sobre as fontes da Cartografia Maiorquina (séculos XIII-XIV). 2013. 304p. Tese (Doutorado em Geografia). Departamento de Geografia, Universidade de São Paulo, São Paulo, 2013.

NOGUEIRA, Magali Gomes; BIASI, Mario de. Fontes e técnicas da cartografia medieval portulano. Terra Brasilis (Nova Série) [online], Niterói, n. 4, p. 1-19, 2015. Disponível em: https://journals.openedition.org/terrabrasilis/1240\#abstract. Acesso em 8 set. 2020.

PANOFSKY, Erwin. Significado nas Artes Visuais. São Paulo: Perspectiva, 2007. (Debates; 99/ dirigida por J. Guinsburg).

PICATRIX. Das Ziel der Weisen von Pseudo-Magriti. Hellmut Ritter e Martin Plessnaer (trad. e Ed.). London: Warburg Institut, 1962 [1933]. (Studies of the Warburg Institut, 27).

PICATRIX. The Latin Version of the Ghayat Al-Hakim. David Pingee (ed.). London: Warburg Institut, 1986.

PINGREE, David. Some of the Sources of the Ghāyat al-hakīm. Journal of the Warburg and Courtauld Institutes, Londres, v. 43, p.1-15, 1980.

SANS, Jaume; RIERA, I. Cresques Abraham, Judio de Mallorca, Maestro de Mapamundis y de Brujulas. New York: Abaris Books, 1978.

SILVEIRA, Aline D. Relação corpo, natureza e organização sociopolítica no Medievo: revelação, ordem e lei. In: NODARI, Eunice Sueli; KLUG, João (orgs.) História Ambiental e Migrações. São Leopoldo: Oikos, 2012. p. 151-166.

SILVEIRA, Aline Dias. Fronteiras da tolerância e identidades na Castela de Afonso $\mathrm{X}$. In: FERNANDES, Fátima Regina (coord.). Identidades e fronteiras no Medievo Ibérico. Curitiba: Juruá, 2013. p. 127-149.

SILVEIRA, Aline Dias da. Saber em movimento na obra andaluza Gāyat al-hakīm, o Picatrix: problematização e propostas. Diálogos Mediterrânicos, Curitiba, n. 9, p. 169- 188, 2015. 
STUCKRAD. Kocku. Le Picatrix dans le De Vita de Masile Ficin, un exemple de transferts Culturels. In: BOUDET, Jean-Patrice; CAIOZZO Anna; WEILL-PAROT, Nicolas (ed.). Images et magie: Picatrix entre Orient et Occident. Paris: Honore Champion, 2011. p. 331-340.

WARBURG, Aby. Gesammelte Schriften. Band I. Leipzig: Bibliothek Warburg, 1932.

WARBURG, Aby. Histórias de fantasma para gente grande: escritos, esboços e conferências. São Paulo: Companhia das Letras, 2015.

\section{NOTAS}

\section{AUTORIA}

Aline Dias da Silveira: Doutora. Professora Associada, Universidade Federal de Santa Catarina, Centro de Filosofia e Ciências Humanas, Departamento de História, Florianópolis, SC, Brasil.

Bianca Klein Schmitt. Graduanda, Universidade Federal de Santa Catarina, Centro de Filosofia e Ciências Humanas, Departamento de História, Florianópolis, SC, Brasil.

\section{ENDEREÇO PARA CORRESPONDÊNCIA}

Aline Dias da Silveira. Departamento de História, Universidade Federal de Santa Catarina - UFSC Trindade, 88040-970, SC, Brasil.

\section{ORIGEM DO ARTIGO}

Projeto de pesquisa: "Saber, Poder e Transculturalidade: obras astromágicas e o projeto político de Afonso X de Castela".

\section{CONTRIBUIÇÃO DE AUTORIA}

Concepção e elaboração do manuscrito: A. D. Silveira, B. K. Schmitt.

Análise da fonte: A. D. Silveira

Discussão dos resultados: A. D. Silveira, B. K. Schmitt.

Revisão e aprovação: A. D. Silveira, B. K. Schmitt.

\section{FINANCIAMENTO}

Esta pesquisa foi financiada com Bolsa de Iniciação Científica do Conselho Nacional de Desenvolvimento Científico e Tecnológico (CNPq).

\section{CONSENTIMENTO DE USO DE IMAGEM}

Não se aplica.

\section{APROVAÇÃO DE COMITÊ DE ÉTICA EM PESQUISA}

Não se aplica.

\section{CONFLITO DE INTERESSES}

Não houve conflito de interesses.

\section{LICENÇA DE USO}

Este artigo está licenciado sob a Licença Creative Commons CC-BY. Com essa licença você pode compartilhar, adaptar e criar para qualquer fim, desde que atribua a autoria da obra. 


\section{PUBLISHER}

Universidade Federal de Santa Catarina. Programa de Pós-Graduação em História. Portal de Periódicos UFSC. As ideias expressadas neste artigo são de responsabilidade de seus autores, não representando, necessariamente, a opinião dos editores ou da universidade.

\section{EDITORES}

Flávia Florentino Varella (Editora-chefe)

Tiago Kramer de Oliveira

Waldomiro Lourenço da Silva Júnior

\section{HISTÓRICO}

Recebido em: 5 de fevereiro de 2020

Aprovado em: 16 de junho de 2020

Como citar: SILVEIRA, Aline Dias da; SCHMITT, Bianca Klein. "Ymage del mon": o corpo e o mundo no Atlas Catalão de Cresques Abraham, 1375. Esboços, Florianópolis, v. 27, n. 46, p. 511-533, set./ dez. 2020. 